\title{
Estruturas Antigas, Tectônica Recente: Diferentes Controles na Evolução do Relevo na Região das Altas Cristas Quartzíticas da Mantiqueira Meridional
}

\section{Ancient Structures, Recent Tectonics: Different Controls in Relief Evolution in the Region of High Quartzitic Crests of Southern Mantiqueira}

\author{
Roberto Marques Neto ${ }^{1 *} \bowtie$ (iD), Felipe Pacheco da Silva ${ }^{\square} \bowtie$ (iD, \\ Juliana Alves Moreira ${ }^{1} \varangle$ (iD \\ ${ }^{1}$ Departamento de Geociências, Universidade Federal de Juiz de Fora - \\ Juiz de Fora, Minas Gerais, Brasil. \\ 2 Departamento de Geografia, Instituto de Geociências, Universidade Federal do Rio de \\ Janeiro - Rio de Janeiro, RJ, Brasil \\ Rio de Janeiro, Rio de Janeiro, Brasil. \\ E-mails: feliipe.p@hotmail.com (FPS); julianaalvesmoreira22@gmail.com (JAM). \\ *E-mail para correspondência: roberto.marques@ufjf.edu.br (RMN).
}

Recebido (Received): 15/02/2019

Aceito (Accepted): 24/09/2019.

\begin{abstract}
Resumo: As altas cristas da Mantiqueira Meridional figuram como estruturas festonadas pela rede de drenagem que demanda indiretamente o Oceano Atlântico, figurando como uma unidade morfoestrutural cuja geomorfogênese coaduna retração erosiva de escarpas a processos diastróficos morfotectônicos, encerrando um sistema geomorfológico de alta complexidade, onde os efeitos neotectônicos se sobrepõem às expressões geomorfológicas regionais forjadas em estruturas antigas reativadas durante o rifte Continental do Sudeste do Brasil. Com base em abordagens metodológicas voltadas para as interpretações morfoestruturais e morfotectônicas, a pesquisa aqui divulgada identificou importantes aspectos da tectônica ativa atuando na evolução do relevo regional, cuja espacialidade é estabelecida pelas superfícies de base, pela configuração da drenagem e padrão de lineamentos, pelo reconhecimento e mapeamento de feições morfotectônicas e interpretação de seu significado, bem como pela compartimentação da área segundo seu significado morfoestrutural e morfotectônico.
\end{abstract}

Palavras-chave: Morfotectônica; Grandes Escarpamentos; Cristas Quartzíticas.

Abstract: The high crests of Southern Mantiqueira appear as structures scalloped by the drainage network that indirectly demands the Atlantic Ocean appearing as a morphostructural unit whose geomorphogenesis combines cliffs erosive retraction to morphothectonic diastrophic processes enclosing a geomorphological system of high complexity where the neotectonic effects are superimposed to the regional geomorphological expressions forged in old structures reactivated during the Continental rift of Southeastern of Brazil.Based on methodological approaches focused on morphostructural and morphothectonic interpretations the research disclosed here identified important aspects of the active tectonics acting on the evolution of the regional relief whose spatiality is established by base surfaces, by drainage configuration and lineaments pattern by the recognition and mapping of morphothectonic features and interpretation of its meaning as well as by the compartmentalization of the area according to its morphostructural and morphothectonic meaning.

Keywords: Morphotectonic; Greatest Escarpaments; Quartzitic Crests.

\section{Introdução}

Na medida em que o conhecimento acerca do regime neotectônico intraplaca se avoluma, fica clara a imperiosa necessidade de se interpretar os diferentes controles atuantes na evolução do relevo e distinguir as estruturas passivas das eminentemente morfotectônicas, no intuito último de se entender de forma cada vez 
mais precisa e detalhada a sobreposição de diferentes regimes, suas expressões estruturais e geomorfológicas.

Nos trópicos úmidos, a evolução de mantos de intemperismo espessos tendencialmente mascara ou oblitera os elementos estruturais presentes na rocha, como juntas, planos de falha e foliações metamórficas, dificultando a observação, interpretação e medição de elementos planares em campo. Ainda, a visada geocronológica destes procedimentos de análise estrutural de base é deveras relativizada pela impossibilidade de datação absoluta das estruturas, o que exige outras correlações para a interpretação da idade do regime tectônico e para a diferenciação entre estruturas ativas e passivas. Nesse sentido, a interpretação do relevo e da drenagem tem servido como um importante aporte nos estudos focados na tectônica vigente, contribuindo sobremaneira para uma sistematização mais precisa do controle morfotectônico na evolução do relevo e da drenagem. Um rol cada vez mais amplo de abordagens metodológicas tem se proliferado, desde técnicas morfométricas voltadas para a quantificação de fatos geomórficos até métodos geocronológicos mais avançados voltados para a datação de depósitos cenozoicos tectonicamente deformados, passando por procedimentos tradicionais de análise estrutural, como interpretação e extração de lineamentos e medição de estruturas em campo e sua projeção estereográfica. Ainda, alguns trabalhos focam fundamentalmente a interpretação das feições geomorfológicas de nexo morfotectônico, observando capturas fluviais, inflexões e encaixamentos abruptos de canais fluviais, deformação de depósitos e afloramentos rochosos em terraços, assimetria de bacias, escarpas de falha, presença de vales suspensos, ocorrência de estruturas de liquefação, entre outros indícios. Para completar, análises sísmicas e paleossísmicas, estas em grande medida focadas em registros de estruturas de liquefação, tem ganhado campo. Vasta gama de trabalhos realizados no Brasil e no exterior representa o conjunto das abordagens mencionadas, entre os quais alguns são aqui elencados (SAADI, 1990, 1991; SALAMUNI, 1998; SANTOS, 1999; GONTIJO, 1999; RUBIN, 1999; FERREIRA, 2001; CORSI, 2003; ETCHEBEHERE, 2000, 2004; CHIESSI, 2004; MORALES, 2005; HIRUMA, 2007; GARROTE et al. 2008; SILVA e MELO, 2011; MARQUES NETO, 2012; MAIA e BEZERRA, 2014; JACQUES et al. 2014; PINHEIRO e QUEIROZ NETO, 2015; ROY \& SAHU, 2015).

As cristas quartzíticas da Mantiqueira Meridional, na zona da mata do estado de Minas Gerais, figuram como importantes elementos do relevo regional, marcando o contato entre os ramos meridional e setentrional da Mantiqueira (GATTO et al. 1983). Apresentam falhas e dobras vinculadas aos esforços compressivos do final do Pré-cambriano (Ciclo Brasiliano) reativadas a partir dos efeitos diastróficos ligados ao rifte continental do sudeste do Brasil (RICCOMINI, 1989), que engendraram o soerguimento dos horsts da Serra da Mantiqueira e da Serra do Mar e o abatimento da fossa tectônica posteriormente dissecada pelo rio Paraíba do Sul e sua rede de afluentes diretos e indiretos. Estas estruturas antigas apresentam vasto plantel de assinaturas de esforços tectônicos recentes, correspondentes às reativações neogênicas adequáveis ao período neotectônico da Plataforma Brasileira. Cabe ao presente trabalho discutir as relações entre o papel da estrutura e o controle morfotectônico na evolução do relevo no contexto desses grandes escarpamentos.

\section{Procedimentos Metodológicos}

O conjunto de abordagens metodológicas empregado perpassou procedimentos cartográficos, morfométricos e expedientes de análise estrutural e morfotectônica.

Primeiramente foi levada a efeito a delimitação da área de estudo, estimando a ocorrência das altas cristas que se sobressaem de alinhamentos dotados de elevação mais modesta no extremo sul da Zona da Mata Mineira, abarcando também os compartimentos rebaixados existentes entre os grandes alinhamentos a fim de investigar comportamentos diferenciais entre os blocos a partir do estabelecimento de um nível de base de referência, dado pelo rio do Peixe.

A área em questão, uma vez definida e delimitada, foi objeto de uma compartimentação geomorfológica calcada fundamentalmente nas unidades topomorfológicas que se sucedem altitudinalmente, dos compartimentos altimontanos aos intermontanos e depressionários, a semelhança de propostas divulgadas por Cunha e Mendes (2005) e Marques Neto et al. (2017). Por esta concepção, os diferentes níveis topomorfológicos foram discernidos a partir de sua posição altimétrica e da disposição das isolinhas, que revelam a passagem de patamares de cimeira para compartimentos escarpados, de escarpas para patamares reafeiçoados, dos patamares aos morros, sempre mirando o escalonamento topográfico congruente à zonação altitudinal das organizações geomorfológicas presentes. Cartas hipsométricas e de declividade foram geradas em software ArcGIS para subsidiar a compartimentação, levada a efeito com o apoio de dados de radar SRTM (Shutle Radar Topography Mission) e das bases planialtimétricas em escala de 1/50.000 (Santana do Garambéu, SF-23-X-C-V-2; Santa Rita de Jacutinga, SF-23-Z-C-II-2; Santa Bárbara do Monte Verde, SF23-X-C-VI-1; Lima Duarte, SF-23-X-C-VI-3; Bias Fortes, SF-23-X-C-VI-1; Bom Jardim de Minas, SF-23$\mathrm{X}-\mathrm{C}-\mathrm{V}-4)$. 
Além da compartimentação, as bases planialtimétricas também foram utilizadas para a quantificação das superfícies de base a partir da hierarquia fluvial, as quais fornecem valiosas informações acerca do quadro tectono-erosivo mais recente (JAIN, 1984). São representadas cartograficamente a partir de isobases que correspondem a uma superfície hipotética determinada pela intersecção entre a rede de drenagem de ordem similar com a superfície erosiva associada à reorganização da rede hidrográfica. No presente trabalho foram obtidas a partir dos procedimentos levados a efeito por Salvador \& Pimentel (2009), pautados fundamentalmente na interpolação pelo sistema IDW do ArcGIS. Primeiramente foi gerado um mapa com as isobases na escala de 1/50.000 com o software ArcGIS, ambiente no qual também foi extraída a rede de drenagem do modelo digital de elevação (MDE), hierarquizada segundo Strahler (1952). Doravante, foram selecionados os canais de $2^{\mathrm{a}}$ ordem, convertidos ao formato raster com valor 1; posteriormente, tal arquivo foi combinado com o MDE através de multiplicação, obtendo-se assim as altitudes locais. Por fim, foi empreendida a vetorização do arquivo para geração de outro arquivo de pontos cotados, que foram interpolados pelo protocolo IDW.

Como parâmetro morfométrico complementar foi calculado o Fator de Assimetria de Bacias de Drenagem (FABD) (HARE e GARDNER, 1985) como auxílio na interpretação de possíveis basculamentos de blocos sinalizados por migração lateral de canais fluviais. O índice é mensurado pela fórmula $[\mathrm{FABD}=100$ (Ar/At)], onde Ar é a área da margem direita do curso d'água principal e At é a área total da bacia. Segundo Salamuni (1998), valores inferiores a 50 correspondem a um basculamento da margem direita da bacia, ao passo que valores superiores à meia centena são indicativos de basculamento da margem esquerda. Para a área de estudo o índice em questão foi calculado para bacias de $5^{\circ}$ ordem ou superiores pela referência escalar de 1/50.000.

Concomitantemente ao trato morfométrico foi levada a efeito a extração dos lineamentos estruturais, interpretados a partir de dados de radar SRTM em relevo sombreado. A interpretação levou em conta quatro ângulos de iluminação azimutal $\left(45^{\circ}, 90^{\circ}, 315^{\circ}\right.$ e $\left.360^{\circ}\right)$, uma vez que cada uma dessas angulações realça de forma mais contundente algumas orientações de lineamentos em detrimento de outras, permitindo assim uma interpretação mais segura e abrangente. Os lineamentos foram interpretados separadamente para o relevo e para a drenagem, gerando-se, para ambos, rosetas representativas em intervalos angulares de $10^{\circ}$, lançandose mão do software Georient $\odot$.

O trato morfométrico e estrutural foi conjugado à interpretação do relevo e da drenagem voltada para a identificação de evidências de tectônica ativa, como escarpas de falha, facetas triangulares e trapezoidais, rupturas de declive, capturas fluviais associadas à shutter ridges, estrangulamento de planícies fluviais, etc. $\mathrm{O}$ reconhecimento destes fatos geomórficos se deu em campo e pela interpretação das folhas topográficas e produtos de sensoriamento remoto, sendo georreferenciados e representados por símbolos apropriados em um mapa de feições morfotectônicas.

Doravante, a pesquisa convergiu para uma etapa de síntese objetivada na compartimentação da área segundo seu significado morfoestrutural e morfotectônico. O nexo morfoestrutural foi interpretado a partir da correlação entre os compartimentos geomorfológicos, lineamentos estruturais, drenagem e base geológica. Dialogicamente, os dados morfométricos associados à interpretação do relevo e da drenagem subsidiaram a interpretação do significado morfotectônico dos compartimentos, estimando os seguintes aspectos: (A) ocorrência de escarpas de falha; (B) indicadores em anomalias de drenagem; (C) presença de bacias assimétricas; (D) zonas erosivas; (E) zonas de estocagem sedimentar (F) Orientação dos elementos planares em estruturas recentes, fazendo-se medições em juntas e falhas transcorrentes (além de bandamentos em rocha), concentrados nas cristas quartzíticas onde as exposições são mais conspícuas.

\section{Resultados}

\subsection{Apresentação dos Dados Tectono-estruturais}

Um relevo caracterizado pela presença de altas cristas, dominantemente compostas por quartzitos grosseiros, avulta como volumetria topográfica de destaque no setor meridional da Zona da Mata Mineira, na extremidade NE da Mantiqueira Meridional (GATTO et al. 1983). Tais cristas perfazem domínios altimontanos ladeadas por relevo policonvexo dominantemente gnáissico em morros e morrotes nos terrenos intermontanos, com os quais estabelecem desníveis que podem superar 500 metros. Correspondem às zonas de cisalhamento pré-cambrianas sucessivamente reativadas e são balizadas por quartzitos intercalados a algumas lentes de gnaisses e xistos, conforme indicado no mapeamento apresentado por Heinek (1991), perfazendo um estoque litológico que se encerra na Megassequência Andrelândia (HEILBRON et al. 2004) (Figura 1). 


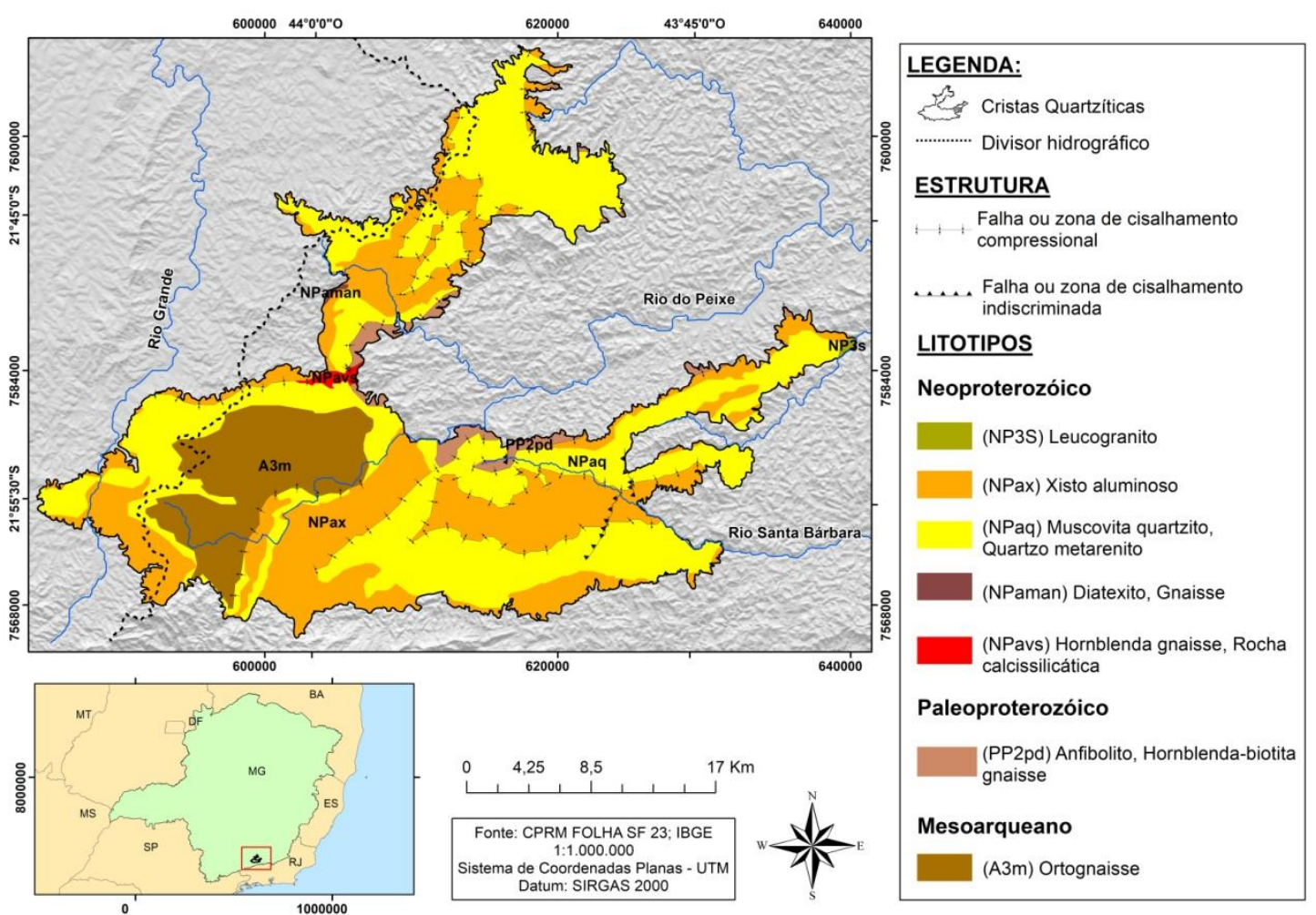

Figura 1: Localização e esboço geológico da área de estudo.

A extremidade nordeste da Mantiqueira Meridional é caracterizada por fortes amplitudes altimétricas demarcadas entre as linhas interfluviais das altas cristas, e os terrenos intermontanos distintamente mais rebaixados, controlados pelos níveis de base regionais que demandam escalonadamente o Oceano Atlântico. São coletores de uma rede de canais de forte competência erosiva que exerce distinta erosão diferencial nos litotipos gnáissicos e nos xistos, em contraste aos quartzitos que balizam os altos topográficos referenciados nas cristas (Figura 2).
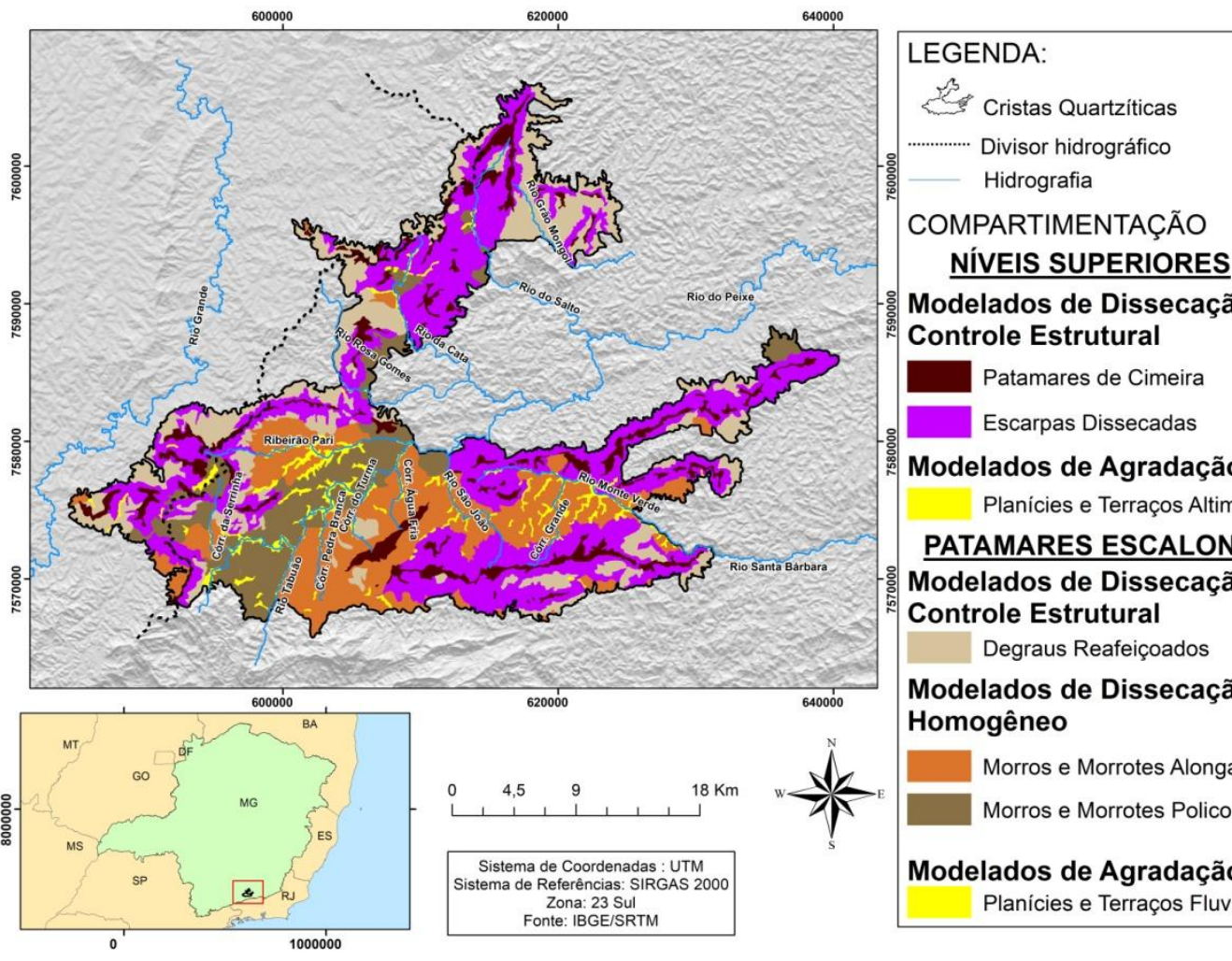

Modelados de Dissecação em

Controle Estrutural

Patamares de Cimeira

Escarpas Dissecadas

Modelados de Agradação

Planícies e Terraços Altimontanos

PATAMARES ESCALONADOS

Modelados de Dissecação em

Controle Estrutural

Degraus Reafeiçoados

Modelados de Dissecação

Homogêneo

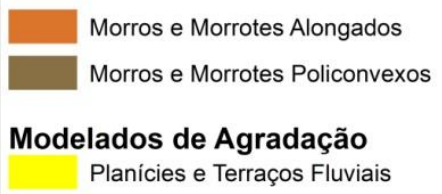

Figura 2: Compartimentação da região das altas cristas quartzíticas em unidades topomorfológicas. 
As altas cristas perfazem os mais extensos alinhamentos topográficos da área de estudo, definindo lineamentos estruturais coniventes às direções das linhas interfluviais, segmentados e desalinhados por esforços tectônicos cenozoicos (SILVA et al. 2017). A conspicuidade das estruturas E-W demarcam explicitamente a orientação da Serra Negra e de Lima Duarte, ao passo que a orientação NE-SW tem sua expressão geomorfológica mais contundente na Serra do Ibitipoca, perfazendo ainda outros alinhamentos de patamares e morros talhados em estruturas correspondentes ao sistema rifte continental do sudeste brasileiro, de Riccomini (1989). Estas grandes estruturas são visualizáveis de forma mais contundente nos lineamentos do relevo (Figura 3), e correspondem às direções pré-cambrianas reativadas na fase sin-rifte.

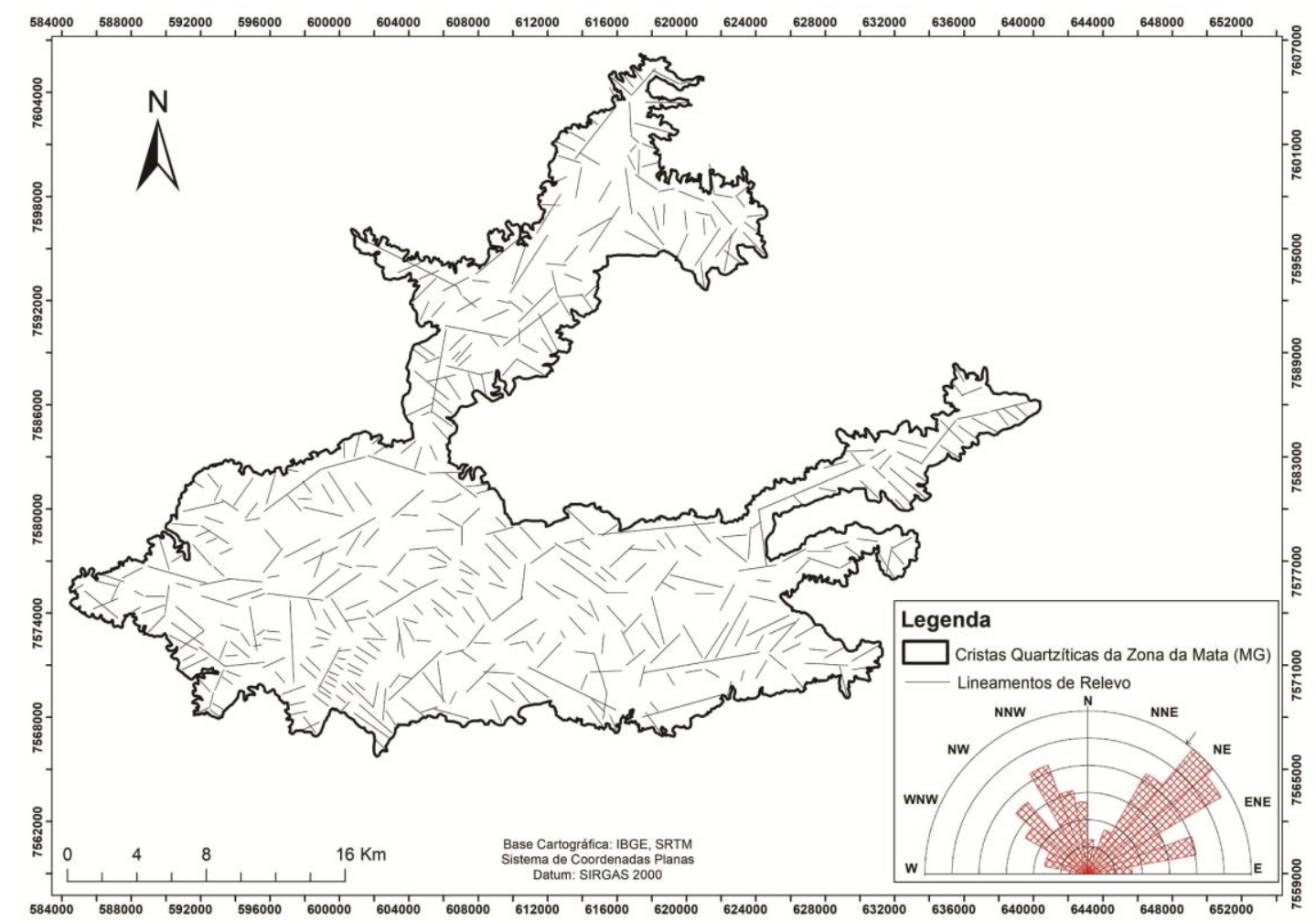

Figura 3: Lineamentos do relevo na região das cristas quartzíticas da Zona da Mata Mineira.

O relevo é significativamente recortado, o que, a rigor, repercute em uma densidade considerável de lineamentos para além das grandes estruturas NE-SW que se distribuem através de interflúvios locais, em grande medida desalinhados por efeitos diastróficos recentes. Até mesmo as altas cristas se encontram em notório desalinhamento por esforços transcorrentes neotectônicos, sobretudo a Serra Negra e a Serra de Lima Duarte, que muito recorrentemente mudam sua orientação interfluvial, o que pode ser apreciado pelas mudanças na orientação dos lineamentos do relevo, bem como no mapa da figura 9.

Alinhamentos topográficos no sentido NW-SE também são conspícuos na área de estudo, perfazendo interflúvios locais que ladeiam canais de pequena extensão adaptados às descontinuidades que seguem essa orientação, comumente afluindo nos canais de orientação NE-SW adaptados ao rifte. Essa orientação é registrada fundamentalmente na drenagem (Figura 4), e corresponde à reativação neogênica do rifte (SILVA e MELLO, 2011), sendo, portanto, vinculados às estruturas neotectônicas, dialogando com os dados apresentados pelos autores supracitados.

Os principais canais fluviais que dissecam a área perfazem diferentes orientações, adaptando-se a diferentes sistemas de falhas e juntas e respondendo às solicitações tectônicas recentes, a causa primeira do rio do Peixe, principal coletor regional, intercalar segmentos encaixados e extensões com planície fluvial bem desenvolvida. Essa intercalação em blocos em soerguimento e subsidência que caracteriza a atividade de dissecação do rio do Peixe é distintamente marcada nas mudanças de direção do canal. 


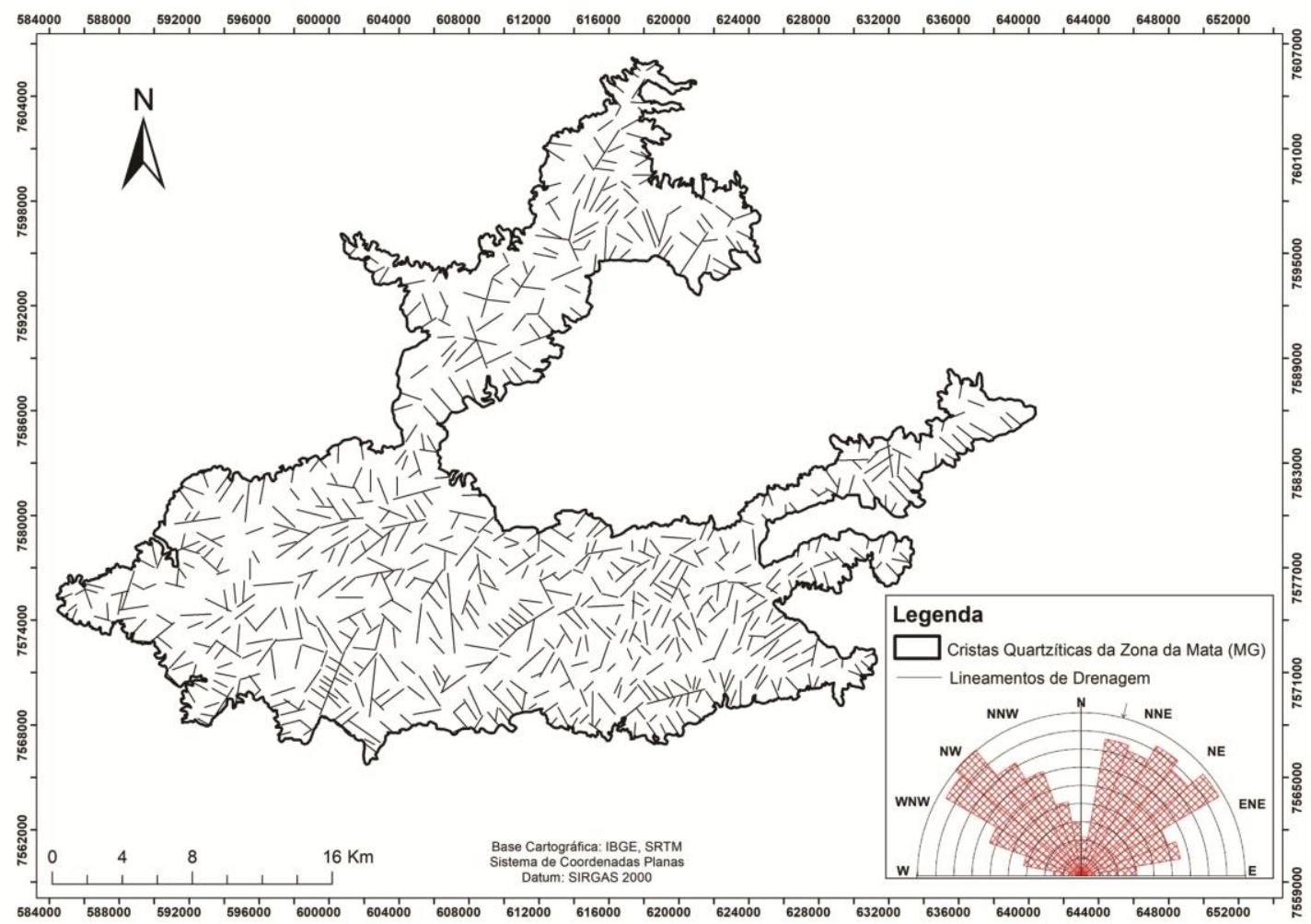

Figura 4: Lineamentos da drenagem na região das cristas quartzíticas da Zona da Mata Mineira.

Estruturas NE são copiosas e representam os canais ou segmentos de canais adaptados às falhas de direção NE-SW reativadas na fase rifte, além de vários canais importantes orientados segundo a direção N-S, como o córrego da Pedra Branca, do Tabuão e do Turuma. A direção E-W não se faz recorrente para a drenagem, destacando-se apenas o ribeirão Pari como curso d'água de importância que perfaz o referido controle. Chama a atenção, no contexto da malha hidrográfica contida na área de estudo, as mudanças de direção de vários cursos d'água importantes, que se arranjam tanto nas estruturas NE-SW como naquelas de orientação NW-SE, caso do rio da Cata, do Salto, Grão-Mogol, São João e do próprio rio do Peixe. Ainda, o incremento de cursos de orientação N-S denota franca sobreposição de esforços deformacionais temporalmente distintos, entre os quais os sistemas NE-SW sinalizam heranças e/ou reativações da fase rifte, os sistemas NW-SE a primeira reativação do rifte, e as direções N-S e estruturas menores como as de direção E-W provavelmente indicando campos de tensão mais recentes (SILVA e MELLO, 2011), bem marcados no mapa mundial de tensões tectônicas organizado por Zoback et al (1989).

A orientação N-S é bem definida na drenagem de padrão paralelo, dispersada a partir das cristas E-W (Serra Negra e Serra de Lima Duarte) que, por conseguinte à sua orientação, vertem canais na direção perpendicular. Ladeados a esses canais se organizam interflúvios secundários paralelos formados pelo reafeiçoamento das cristas e geração de patamares em noses que se projetam em direção ao vale de ordem imediatamente superior, e que foram mapeados como degraus reafeiçoados (Figura 2). Esta rede de canais demanda o nível de base estabelecido pelo rio Santa Bárbara entre os dois pilares tectônicos mencionados, mantendo a mesma orientação e coalescendo ao nível de base imposto pelo rio do Peixe, que festona as cristas a 700 metros de altitude e estabelece, por conseguinte, uma amplitude altimétrica de quase 900 metros em relação aos níveis de cimeira regionais. Esse controle N-S engendra desvio abrupto do rio Santa Bárbara, por sua vez coincidente ao deslocamento da Serra de Lima Duarte, que muda abruptamente a direção do canal em demanda ao gráben adjacente em resposta ao mesmo controle.

Verifica-se, a luz do exposto, uma relação estreita entre as direções e padrões de drenagem com a compartimentação geomorfológica marcada por notório escalonamento topográfico e na qual os limites entre os compartimentos são abruptos e assinalados por rupturas de declive de forte significado morfotectônico, normalmente coincidentes às mudanças no nível hierárquico da rede de drenagem. O mapa das superfícies de base (Figura 5) gerado para a área auxilia o estabelecimento de uma espacialidade para os efeitos neotectônicos e suas relações com as estruturas preexistentes. 


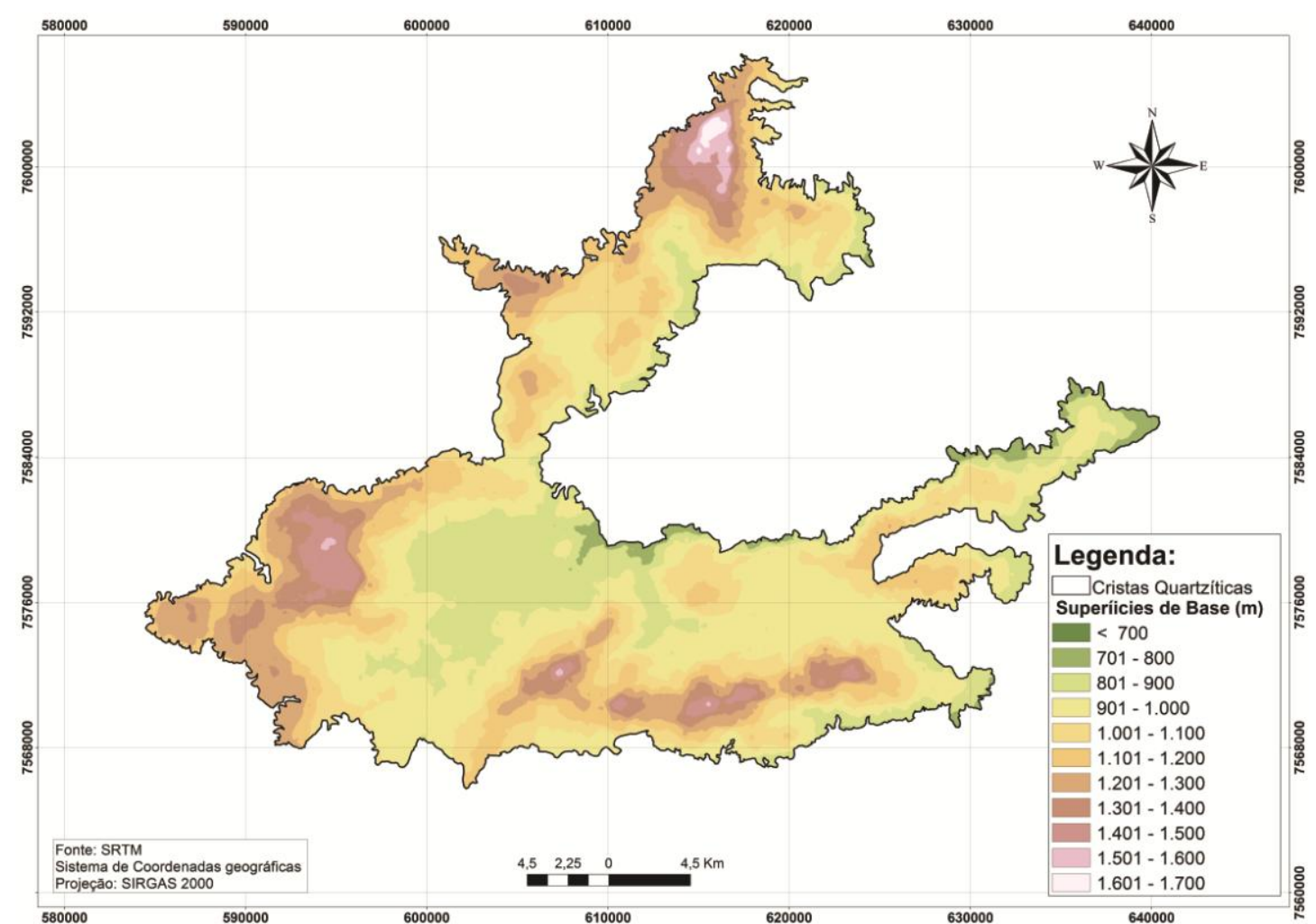

Figura 5: Superfícies de base mensuradas para a região das altas cristas da Mantiqueira Meridional.

Distintamente, a aproximação de isobases coincide com as referidas rupturas de declive, e auxiliam na delimitação de blocos integrados em curvas de isovalores semelhantes. Nessa linha, o domínio das cristas pode ser estabelecido acima $1000 \mathrm{~m}$, e nas áreas intermontanas fica distinto o nível de base regional estabelecido pelo rio do Peixe, posicionado em torno de 700 metros, avultando uma dissecação mais homogênea em morros dominantemente convexos interceptados por baixas cristas, configuração bastante recorrente na região.

$\mathrm{Na}$ extremidade norte, dada pela Serra do Ibitipoca, e no ramo sul delimitado pela Serra Negra, antipodal ao anterior, os contatos são mais abruptos e resultam em uma aproximação mais pronunciada das isolinhas, sugerindo um controle tectônico mais expressivo. Na parte sudeste, o ramo da Serra da Mantiqueira que avança delimitando a linha interfluvial da bacia do Paraíba do Sul associa um maior espaçamento das curvas de isovalores à formação de um arco côncavo no front escarpado voltado para o leste, o que denota uma retração mais expressiva dessas escarpas dissecadas pelos afluentes da margem direita do rio do Peixe em seu alto curso. Nesse sentido, as superfícies de base são marcadoras eficientes dessas diferenças tectonoerosivas que por vezes variam substancialmente em um sistema geomorfológico.

\subsection{Discussã̃o}

As evidências reunidas mostram que a área de estudo admite uma compartimentação que coaduna um significado morfoestrutural e morfotectônico, congregando (A) um conjunto de horsts prevalentemente reativados, e que partilham do grande horst da Mantiqueira Meridional, (B) um conjunto de blocos baixos que congrega um minigáben dissecado pelo rio Monte Verde e uma zona de entrada erosiva em franca dissecação, e (C) um conjunto de morros e patamares escalonados tectonicamente reativados (Figura 6).

Esse esquema guarda relações estreitas com a compartimentação geomorfológica, pelo qual o Bloco A se refere aos domínios altimontanos, e pertencem aos níveis superiores da Mantiqueira Meridional, que na região foram festonados pela passagem do rio do Peixe, pertencente ao conjunto da drenagem que contrariou a inversão forçada pelo soerguimento plataformal e se instalou buscando o nível de base do Oceano Atlântico em abertura. Com o festonamento, a extremidade NE da Mantiqueira Meridional foi amputada do horst contínuo, resultando em três pilares tectônicos subnivelados às cimeiras regionais, porém desarticulados em função das frentes erosivas abertas pela rede de canais afluentes do rio do Peixe, e que confinam zonas deprimidas (Bloco B). 


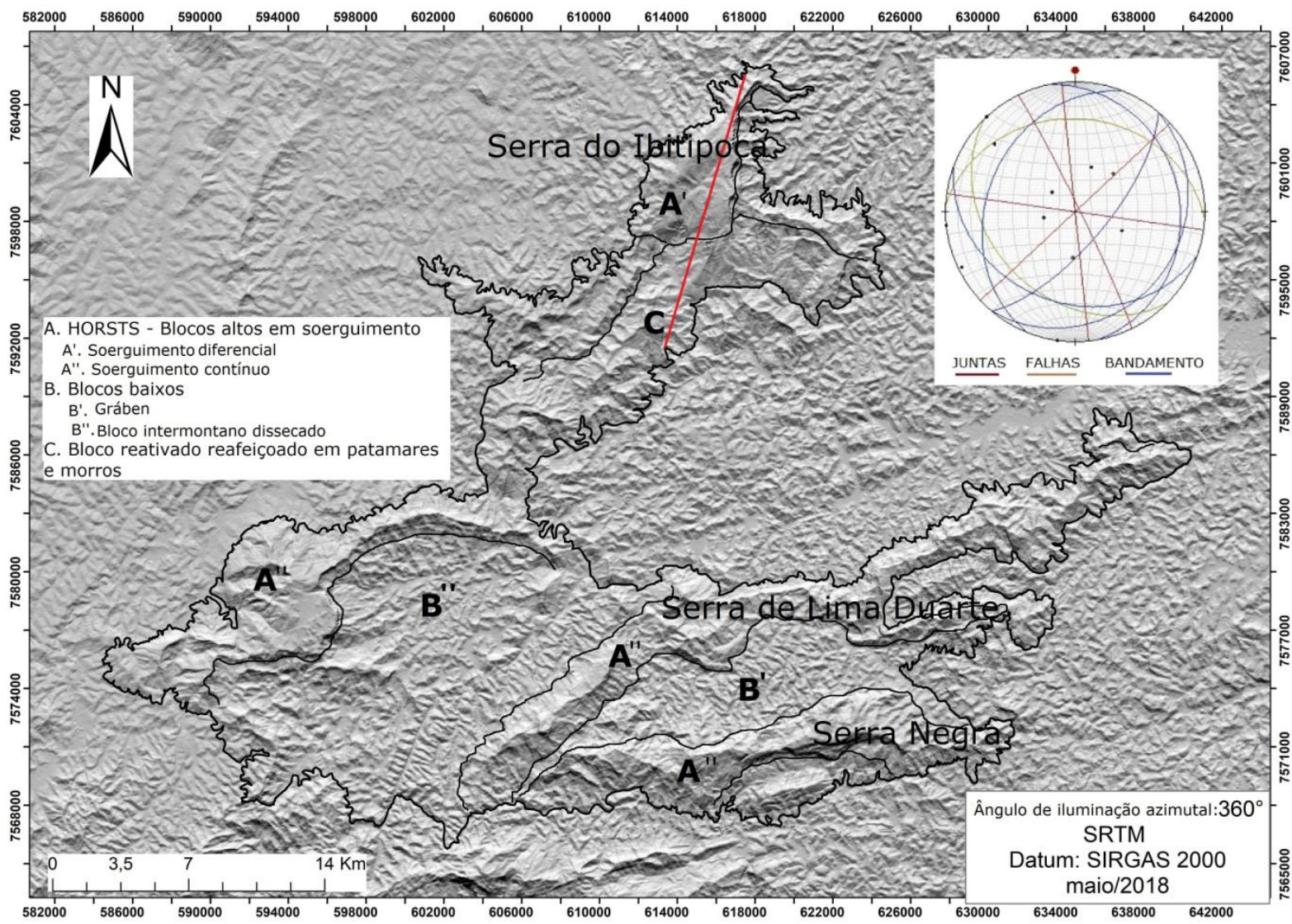

Figura 6: Compartimentação morfotectônica na região das cristas quartzíticas da Zona da Mata Mineira.

No contexto do Bloco A cabe ainda a diferenciação de um domínio morfotectônico simbolizado por A', concernente ao ramo setentrional da Serra do Ibitipoca, um bloco distintamente elevado em forma de cunha que estabelece contato tectônico com os terrenos adjacentes dados por escarpas de falha, e que se sobreleva em rupturas de declive abruptas até mesmo em relação ao restante dessa estrutura. Essa condição fica latente no mapa de superfícies de base pela aproximação anômala das isolinhas, bem como pelas escarpas de falha que impõem soleiras tectônicas talhadas nos maiores rejeitos verticais averiguados em toda a área de estudo durante as expedições de campo. Disso resulta uma drenagem em padrão paralelo a contorcido, cujo arranjo é distintamente influenciado por capturas locais.

A Figura 7 consiste na sobreposição do perfil topográfico atual a um perfil paleotopográfico gerado pelo protocolo Seppômen (MOTOKI et al. 2008) em uma malha quadrática de $2 \mathrm{~km} \times 2 \mathrm{~km}$. Muito embora o presente artigo não esteja estabelecido nessa abordagem, a visualização dos perfis sobrepostos é atinente às discussões em lume, uma vez que revela altitudes mais elevadas nos tempos atuais para o compartimento A', corroborando com a interpretação de um soerguimento preferencial desse bloco. Parte da linha de topografia atual posicionada acima da linha paleotopográfica sugere fortemente que o bloco vem soerguendo, a despeito das baixas taxas de desnudação em quartzitos. O restante do horst se unifica em um compartimento A", concernente a um conjunto de blocos em soerguimento contínuo e prevalente, sendo A' diferenciado em função das fortes evidências de soerguimento preferencial.

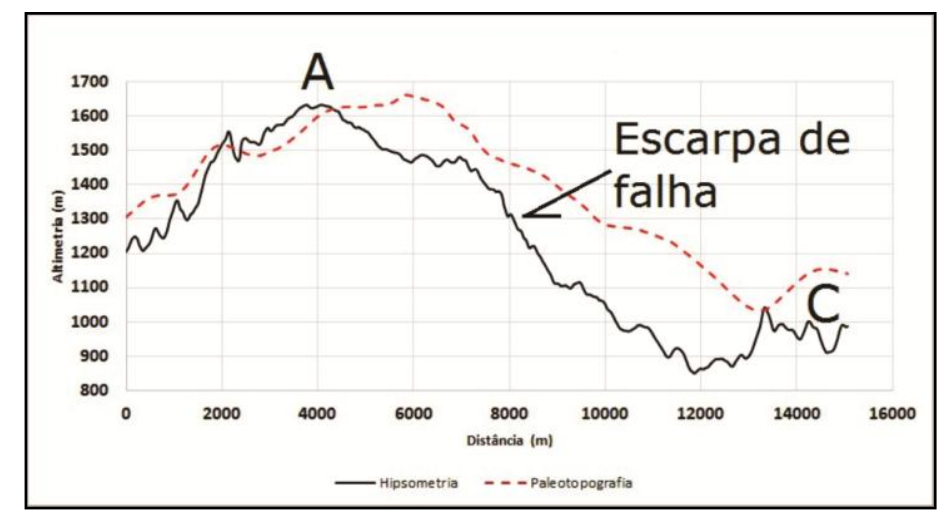

Figura 7: Perfil topográfico (linha contínua) e paleotopográfico (tracejado) sobrepostos no contato entre os compartimentos A' e C. 
Ainda que seja evidente a retração da escarpa, que em parte explora níveis xistosos e gnáissicos, é notória a acentuação do declive no espelho de falha e a sobrelevação dos patamares de cimeira, que se destaca a despeito da resistência dos quartzitos à denudação, condição bastante explícita em campo. Nesses patamares, antigas dobras recumbentes e sistemas de juntas entrecruzadas em diferentes direções (NE-SW, N-S e E-W) de geração pós-miocênica revelam a sobreposição de controles, bem como a existência de contatos locais. Foram encontrados, por exemplo, ângulos mais baixos de mergulho na direção NW, ao passo que intensidades médias foram anotadas em bandamentos que mergulham para SE. As juntas que interceptam perpendicularmente esses bandamentos apresentam extensão relativamente restrita (métrica a decamétrica) e ângulo mais elevado, e figuram como produtos de esforços mais recentes, uma vez que truncam estruturas mais desenvolvidas presumivelmente mais antigas.

As terras baixas (B) são representadas por um gráben de orientação NE-SW confinado entre a Serra Negra e a Serra de Lima Duarte (B') e por um bloco dissecado pelos afluentes do rio do Peixe (B'), delimitando um conjunto de morrarias embasadas por ortognaisses. Nesses compartimentos a dissecação é intensa e francamente assinalada pelo distinto rebaixamento da paisagem, o que fica evidente na imagem radarmétrica da Figura 6, que mostra diferença textural contrastante na retaguarda oeste das cristas por efeito da passagem para a bacia do rio Grande, referenciada pelas linhas interfluviais estabelecidas nos compartimentos A' e A". Com a transposição das bacias mais próximas do Oceano Atlântico em demanda aos níveis planálticos interiores, a textura mais lisa insinua uma maior preservação das superfícies geomorfológicas no Planalto do Alto Rio Grande.

O rio do Peixe, por sua vez, avança planalto adentro mediante o entalhe do ribeirão Rosa Gomes, um de seus principais formadores, se aproximando dos afluentes da margem direita do rio Grande. Nesse setor, entre a sede municipal de Bom Jardim de Minas até a passagem do ribeirão Rosa Gomes, o rio Grande apresenta sua máxima aproximação do divisor das bacias que drenam em demanda ao rio Paraíba do Sul. A entrada da referida frente de dissecação desencadeou capturas nas faixas interfluviais estreitas engendradas pelo recuo das cabeceiras da bacia do rio do Peixe. No entanto, a proximidade do rio Grande impõe um nível de base também próximo, o que favorece a energia erosiva de seus afluentes, ainda que estes estejam muito menos desnivelados em relação ao seu nível de base. Distintamente, entre as cabeceiras do córrego Porteira de Chave (bacia do rio do Peixe) e da Ponte Alta (bacia do Rio Grande) é que as linhas erosivas estão mais próximas, e as capturas locais sinalizam para uma dinâmica erosiva bastante funcional, com potencial, inclusive, de capturar o próprio rio Grande a partir dessa zona e transferir seu caudal à montante para o rio do Peixe.

A compartimentação proposta também discerniu um Bloco $\mathrm{C}$ transicional entre os domínios altimontanos do Bloco A, a leste do alinhamento que concerne a Serra do Ibitipoca, no contato com o conjunto de morros convexos dos níveis intermontanos. Essa unidade é marcada pela presença de soleiras tectônicas que truncam níveis altimétricos distintos, porém formados por estruturas dominantemente NE-SW, sugerindo, conforme frisado, um soerguimento diferencial do nível mais elevado a NW (Bloco A'). Essa possibilidade é aventada a partir dos argumentos anteriormente expostos, e reflete a continuidade dos esforços deformacionais atuando ao longo do Cenozoico, ainda que uma maior precisão temporal esteja em aberto.

Os rios que dissecam os blocos A e B no sentido N-S são os que apresentam as bacias mais assimétricas, denotando intenso controle no contato entre os horsts da Serra Negra e da Serra de Lima Duarte e o gráben correlato (Figura 8). No entanto, o contato entre o bloco A e C também engendra um padrão de média assimetria para as bacias do rio do Salto, da Cata e Rosa Gomes, com mudança de direção N-S para NW-SE, direção esta pela qual estes canais interceptam as estruturas NE-SW.

Para além das evidências tectônicas, as unidades interpretadas também se diferenciam em seus aspectos estruturais, estando os horsts altimontanos balizados em quartzitos com algumas lentes de xistos e gnaisses, e os domínios intermontanos associados a gnaisses e xistos emoldurando geoformas convexas a semitabulares, o que fica latente em remissão à figura 1 . No extremo sul da área de estudo a erosão diferencial também se estabelece no contato entre quartzito e xistos. Entretanto, o contato entre os compartimentos é dado por soleiras rochosas em abruptas escarpas de falha, e as evidências de reativações neotectônicas sobejam distribuídas no relevo e na drenagem: escarpas de falha com facetas trapezoidais, desalinhamentos interfluviais, vales suspensos desarticulados dos níveis de base atuais, entalhe vertical profundo de canais fluviais, presença de terraços rochosos, assimetria bem marcada em bacias de drenagem, migração lateral de canais fluviais, etc. 


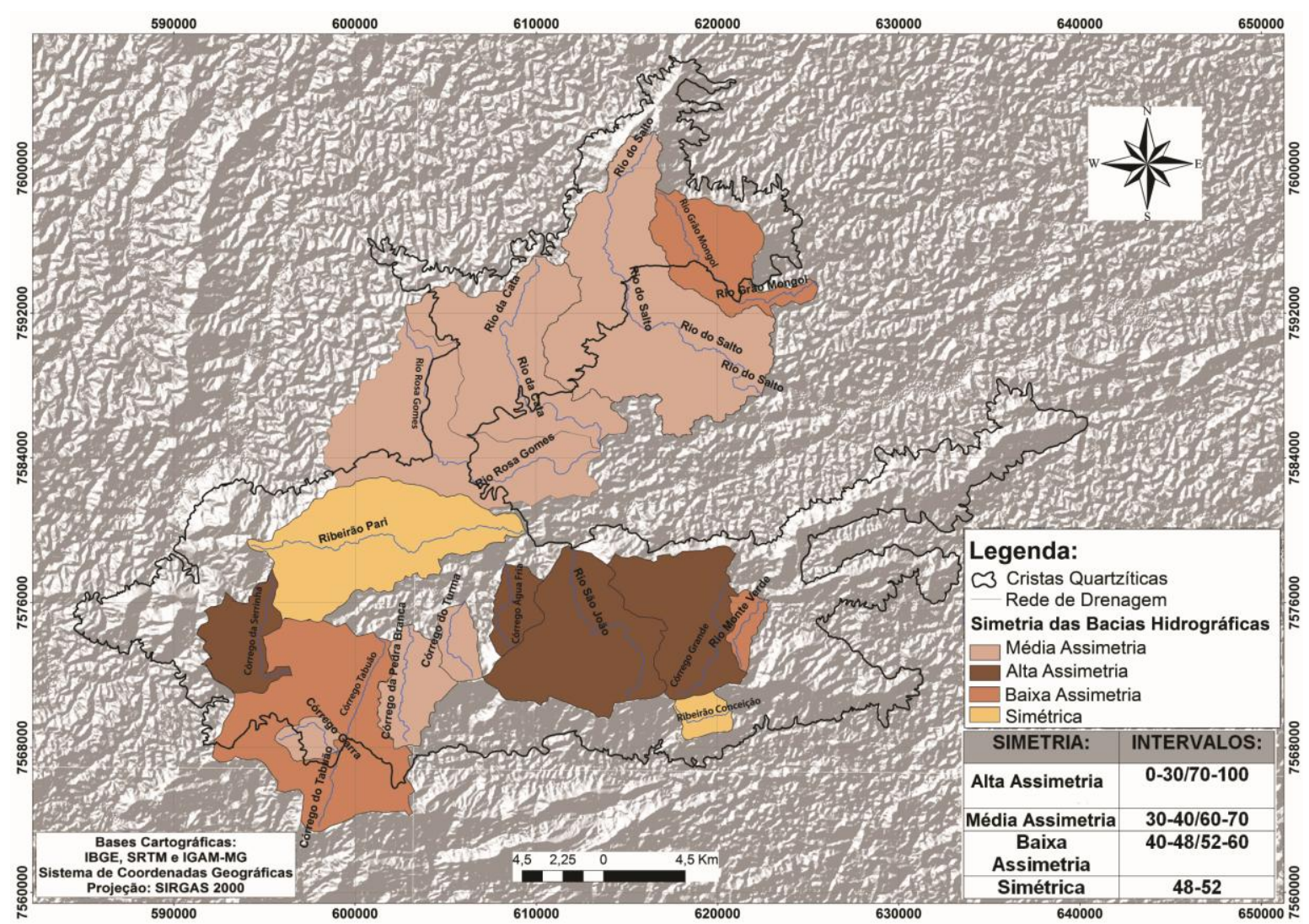

Figura 8: Assimetria das principais bacias de drenagem da área de estudo.

Os fatos geomórficos que indicam controle tectônico sobreposto às estruturas antigas, para além do conjunto de evidências aventadas e colocadas em discussão, influenciaram diretamente a compartimentação morfotectônica aqui proposta. A espacialidade de tais evidências se espraia por todos os compartimentos discernidos, assumindo algumas características e padrões. A Figura 9 espacializa algumas dessas evidências distribuídas pelos compartimentos, e que foram elencadas a partir de sua exequibilidade de representação.

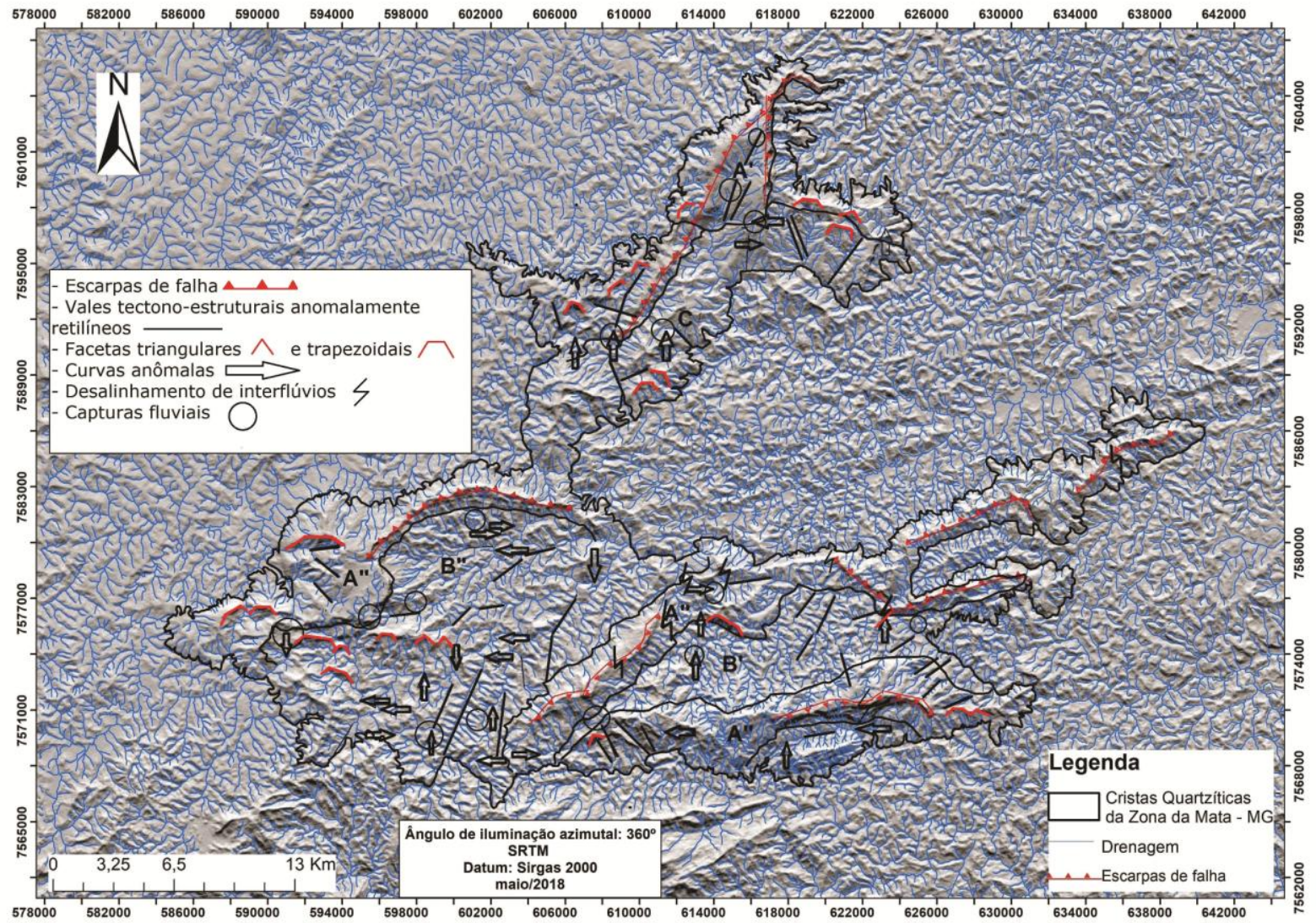

Figura 9: Feições morfotectônicas na região das cristas quartzíticas da Mantiqueira Meridional. 
É notório que a distribuição das feições morfotectônicas guarda relações com o quadro morfoestrutural, bem como com a compartimentação morfotectônica que diferencia os blocos altos e baixos. Nesse sentido, as escarpas de falha são feições típicas do Bloco A, e estabelecem as diagonais que determinam os limites com os compartimentos adjacentes. É no domínio altimontano, ainda, onde avultam as facetas mais bem preservadas, ainda que algumas não tenham sido marcadas em prioridade ao traçado das escarpas de falha, evitando a poluição cartográfica. Também é notório o facetamento no Bloco $\mathrm{C}$, sinalizando a reativação desses patamares com reafeiçoamento dos topos e altas vertentes e rehierarquização da drenagem.

Os horsts figuram como os principais elementos geomorfológicos da área de estudo, e, conforme demonstrado, caracterizam-se por aspecto escarpado e linhas de cumeada contínua ou facetada pela drenagem transversal, encarcerando uma série de vales altimontanos preenchidos com material coluvial e desarticulados de seus níveis de base. Além disso, os grandes alinhamentos sofrem mudanças constantes de direção, por vezes muito bruscas, como ocorre na Serra de Lima Duarte, sugerindo uma interferência flagrantemente tectônica, com provável influência de falhas transcorrentes interceptando as falhas normais de expressão geomorfológica regional, dadas pelas cristas e seu expressivo rejeito vertical.

O controle morfotectônico na drenagem é onipresente, com capturas e curvas anômalas em toda a área de estudo, com notório incremento nos domínios intermontanos, onde a drenagem encontra-se mais evoluída e desenvolve padrões mais complexos em comparação ao paralelismo vigente no domínio das cristas (Bloco A), onde os canais são encaixados e tendem a retilinidade. O controle na drenagem pode ser apreciado de forma mais abrangente no mapa de lineamentos, uma vez que na FIGURA 8 foram marcadas apenas as extensões retilíneas mais significativas, congruente à pré-seleção de feições que foi levada a efeito na definição dos elementos a serem representados.

\section{Conclusões}

A região das cristas quartzíticas festonadas da Mantiqueira Meridional é geomorfologicamente peculiar, uma vez que integra a rede de drenagem que não inverteu para o interior durante o rifteamento plataformal e soerguimento da fachada atlântica, sendo assim uma região geomorfológica estratégica para a compreensão da evolução do relevo no domínio dos grandes escarpamentos da margem rifte do sudeste brasileiro. Cada vez mais, estudos que focam a compartimentação e a espacialidade do relevo, o controle tectônico e os processos denudacionais tem se disseminado nos domínios de relevos montanhosos do Planalto Atlântico, ampliando as associações e correlações regionais e dando maior clareza a respeito dos diferentes controles atuantes na evolução cenozoica desses modelados.

Com regime erosivo controlado pelo nível de base imposto pelo rio Preto, as cristas quartzíticas figuram como unidades morfoestruturais preservadas do consumo erosivo que tende a retrair os grandes escarpamentos da fachada atlântica. Para além do controle estrutural, essa região geomorfológica congrega, a luz dos resultados apresentados e discutidos, um vasto rol de evidências de controle tectônico. Malgrado os processos de recuo erosivo das escarpas, é muito evidente o caráter morfotectônico dessas cristas pela geometria retilínea ou angulosa em facetas trapezoidais, pela presença de escarpas de falha e vales suspensos, entre outras evidências que sustentam a o papel da tectônica na manutenção desses grandes escarpamentos.

Ainda são relativamente escassos os dados de denudação geoquímica para as litologias quartzíticas existentes no domínio dos grandes escarpamentos sob a influência do rifte sudeste, o que seria de grande valia para fins de comparação com as taxas mensuradas em outros litotipos, como sienitos, gnaisses e granitos, possibilitando uma ampliação das interpretações conjuntas entre o controle tectônico e os processos denudacionais na evolução de escarpas de margem rifte. Na área de estudo em específico, as evidências encontradas associadas às pesquisas preexistentes apontam para um controle tectônico contundente ao longo do Cenozoico, com campos de tensão reconhecidos e bem marcados, o que aproxima a evolução do relevo regional ao modelo de um soerguimento isostático e termal da margem rifte. Esse caráter confere diferentes assinaturas morfotectônicas sobre as unidades morfoestruturais geradas na fase sin e pós-rifte e concorre com os processos denudacionais cenozoicos, abrindo frutuoso campo para a aproximação entre os estudos geotectônicos, geoquímicos e geocronológicos, cujo diálogo será cada vez mais imprescindível para o discernimento dos diferentes controles e influências atuantes nas organizações geomorfológicas regionais e locais.

\section{Referências}

BULL, W. B.; WALLACE, R. E. Tectonic geomorphology. Geology, Penrose Conference Report, p. 216, 1985.

CHIESSI, C. M. Tectônica Cenozoica no Maciço Alcalino de Passa Quatro (SP-MG-RJ). 2004. Dissertação (Mestrado em Geologia). Instituto de Geociências, Universidade de São Paulo, São Paulo, 2004. 
CORSI, A. C. Compartimentação morfoestrutural da região do Triângulo Mineiro (MG): aplicado à exploração de recursos hídricos subterrâneos. Rio Claro, 2003, 231p. Tese (Doutorado em Geociências), Instituto de Geociências e Ciências Exatas, Universidade Estadual Paulista.

CUNHA, C. M. L.; MENDES, I. A. Proposta de análise integrada dos elementos físicos da paisagem: uma abordagem geomorfológica. Estudos geográficos, v. 3, n. 1, p. 111-120, 2005.

ETCHEBeHERE, M. L. C. Terraços Neoquaternários no Vale do Rio do Peixe, Planalto Ocidental Paulista: implicações estratigráficas e tectônicas. Rio Claro, 2000. 264p. Tese (Doutorado em Geociências) - Instituto de Geociências e Ciências Exatas, Universidade Estadual Paulista.

ETCHEBEHERE, M. L. C. Aplicação do índice "Relação Declividade-Extensão - RDE" na bacia do Rio do Peixe (SP) para detecção de deformações neotectônicas. Geologia USP-Séries Científicas, São Paulo, v. 4, n. 2, p. 43-56, 2004.

FACINCANI, E. M. Morfotectônica da Depressão Periférica Paulista e cuesta basáltica: regiões de São Carlos, Rio Claro e Piracicaba, SP. Rio Claro, 2000. 222p. Tese (Doutorado em Geologia Regional) Instituto de Geociências e Ciências Exatas, Universidade Estadual Paulista.

FERREIRA, M. F. M. Gemorfologia e análise morfotectônica do alto vale do Sapucaí. Tese (Doutorado em Geociências e Meio Ambiente). 279p. Instituto de Geociências e Ciências Exatas, Universidade Estadual Paulista, Rio Claro, 2001.

GARROTE, J.; HEYDT, G. G.; COX, R. T. Multi-stream order analyses in basin asymmetry: a tool to discriminate the influence of neotectonics in fluvial landscape development (Madrid basin, Central Spain). Geomorphology, v. 102, n. 1, p. 130-144, 2008.

GONTIJO, A. H. F. Morfotectônica do médio vale do Rio Paraíba do Sul: região da Serra da Bocaina, estados de São Paulo e Rio de Janeiro. 1999, 259p. Tese (Doutorado em Geologia). Instituto de Geociências e Ciências Exatas, Universidade Estadual Paulista. Rio Claro, 1999.

HARE, P. W; GARDNER, I. W. Geomorphic indicators of vertical neotectonism along converging plate margins. In: ANNUAL BINGHAMTON GEOMORPHOLOGY SYMPOSIUM. Boston, 1985.

HEINEK, C. A.; SOUZA, H. A.; VASCONCELOS, R. M.; BARRETO, E. L.; GOMES, R. A. A. D.; PINTO, C. P. Programas Levantamentos Geológicos Básicos do Brasil. Companhia de Pesquisa de Recursos Minerais. Folha SF.23-X-C-VI, 1991.

HIRUMA, S. T. Significado morfotectônico dos planaltos isolados da Bocaina. Tese (Doutorado em Geoquímica e Geotectônica). Instituto de Geociências, Universidade de São Paulo. São Paulo, 2007.

JACQUES, P. D.; SALVADOR, E. D.; MACHADO, R.; GROHMANN, C. H.; NUMMER, A. R., Application of morphometry in neotectonic studies at the eastern edge of the Paraná Basin, Santa Catarina State, Brazil. Geomorphology. v. 213, n. 10, 2014.

JAIM, V.E. Geotectónica general. 2. ed. Moscou: Mir Ed., 1984.

MAIA, R. P.; BEZERRA, F. H. R. Inversão neotectônica do relevo na bacia Potiguar, nordeste do Brasil.

Revista Brasileira de Geomorfologia, v. 15, n. 1, p. 61-74, 2014.

MARQUES NETO, R. Estudo evolutivo do sistema morfoclimático e morfotectônico da bacia do Rio Verde (MG), sudeste do Brasil. 2012, 429p. Tese (Doutorado em Geografia), Instituto de Geociências e Ciências Exatas, Universidade Estadual Paulista. Rio Claro, 2012.

MARQUES NETO, R.; MOREIRA, J. A.; SILVA, F. P. (2017) Sistemas geomorfológicos montanhosos e a sua representação cartográfica: mapeamento dos fatos geomórficos no horst do Caparaó (MG/ES). In: PEREZ FILHO, A.; AMORIM, R. R. (Orgs.) Os desafios da Geografia Física nas fronteiras do conhecimento. Campinas: p. 6026-6037.

MORALES, N. Neotectônica em ambiente intraplaca: exemplos da região Sudeste do Brasil. Rio Claro, 2005. 201p. Tese (Livre Docência em Geologia Estrutural e Geotectônica), Instituto de Geociências e Ciências Exatas, Universidade Estadual Paulista.

MOTOKI, A.G.; PETRAKIS, H.; SICHEL, S.E.; CARDOSO, C.E.; MELO, R.C.; SOARES, R.; MOTOKI, K.F. Origem dos relevos do maciço sienítico do Mendanha, RJ, com base nas análises geomorfológicas e sua relação com a hipótese do vulcão de nova Iguaçu. Geociências, v.27 n.1, p.97-113, 2008.

PINHEIRO, M. R.; QUEIROZ NETO, J. P. Neotectônica e evolução do relevo na região da Serra de São Pedro e do baixo rio Piracicaba/sudeste do Brasil. Revista Brasileira de Geomorfologia, v. 16, n. 4, p. 593633, 2015.

ROY, S.; SAHU, A. S., Quaternary tectonic control on channel morphology over sedimentary low land: A case study in the Ajay-Damodar interfluve of Eastern India Geoscience Frontiers, v. 6, n. 19, 2015.

RUBIN, J. C. Sedimentação Quaternária, Contexto Paleoambiental e Interação Antrópica nos Depósitos Aluviais do Alto Rio Meia-Ponte - Goiás/GO. Rio Claro, 1999. Tese (Doutorado em Geociências) - Instituto de Geociências e Ciências Exatas, Universidade Estadual Paulista. 
SAADI, A. Um "rift" neo-cenozóico na região de São João Del Rei - MG; Borda Sul do Cráton do São Francisco. In: $1^{\circ}$ WORKSHOP SOBRE NEOTECTÔNICA E SEDIMENTAÇÃO CENOZÓICA CONTINENTAL NO SUDESTE BRASILEIRO, 1990, Belo Horizonte. Boletim da Sociedade Brasileira de Geologia. Belo Horizonte: SGB, 1990. p. 63-79.

CONTINENTAL NO SUDESTE BRASILEIRO. Ensaio sobre a morfotectônica de Minas Gerais: tensões intraplaca, descontinuidades crustais e morfogênese. Belo Horizonte, 1991. 285p. Tese (Professor Titular), Instituto de Geociências, Universidade Federal de Minas Gerais.

SALAMUNI, E. Tectônica da Bacia Sedimentar de Curitiba (PR). Rio Claro, 1998. Tese (Doutorado em Geologia Regional). Instituto de Geociências e Ciências Exatas, Universidade Estadual Paulista.

SALVADOR, E. D; PIMENTEL, J. Avaliação da neotectônica no município de Angra dos Reis, setor sulfluminense da Serra do Mar, com base em mapas morfométricos gerados em Sistemas de Informações Geográficas (SIG). In: SIMPÓSIO BRASILEIRO DE SENSORIAMENTO REMOTO, 14., 2009, Natal. Anais... Natal: INPE, 2009. p. 3347-3354.

SANTOS, M. Serra da Mantiqueira e Planalto do Alto Rio Grande: a bacia terciária de Aiuruoca e evolução morfotectônica. Rio Claro, 1999. 134p. Tese (Doutorado em Geociências) - Instituto de Geociências e Ciências Exatas, Universidade Estadual Paulista.

SILVA, T. P.; MELLO, C. L. Reativações neotectônicas na Zona de Cisalhamento do Rio Paraíba do Sul (sudeste do Brasil). Revista do Instituto de Geociências, v. 11, n. 1, p. 95-111, 2011.

STRAHLER, A. N. Dynamic basis of geomorphology. Geological Society of American Bulletin, v. 63, p. 923-938, 1952.

ZOBACK, M. L.; ZOBACK, M. D.; ADAMS, J.; ASSUMPÇÃO, M.; BELL, S.; BERGMAN, E. A.; BLÜMLING, P.; BRERETON, N. R.; DENHAN, D.; DING, J.; FUCHS, K.; GAY, N.; GREGERSEN, S.; GUPTA, H. K.; GVISHIANI, K.; JACOB, K.; KLEIN, R.; KNOLL, P.; MAGGIE, M.; MERCIER, J. L.; MÜLLER, B. C.; PAQUIN, C.; RAJENDRAN, K.; STEPHANSSON, O.; SUAREZ, G.; SUTER, M.; UDIAS, A.; XU, Z. H.; ZHIZHIN, M. Global patterns of tectonic stress. Nature, v. 341, p. 291-298, 1989. 